\title{
Plasma secretin and pancreatic bicarbonate response to exogenous secretin in man
}

\author{
W. H. HÄCKI, S. R. BLOOM, P. MITZNEGG, W. DOMSCHKE, S. DOMSCHKE, \\ D. BELOHLAVEK, L. DEMLING, AND E. WÜNSCH
}

From the Departments of Medicine, Royal Postgraduate Medical School, London, and University of Erlangen-Nurenberg, Germany, and the Max Planck Institute of Biochemistry, Munich, Germany

SUMMARY The dose response of duodenal bicarbonate production during synthetic porcine secretin infusions was studied in six healthy volunteers and related to plasma secretin immunoreactivity. Secretin was infused in each individual at four different doses from 0.1 to $2.7 \mathrm{CU} / \mathrm{kg} / \mathrm{h}$, each infusion lasting for 60 minutes. Mean maximal bicarbonate secretion was $33 \pm 4 \mathrm{mEq} / \mathrm{h}$. The secretin plasma level for half maximal bicarbonate response was estimated to be $22 \mathrm{pmol} / \mathrm{l}$. As this level is reported to be achieved by intraduodenal acidification in man, it is concluded that secretin may well play a part in the control of duodenal $\mathrm{pH}$.

Secretin, the first substance to be called a hormone, is generally assumed to be the physiological messenger controlling the duodenal neutralisation of gastric acid by stimulation of pancreatic and biliary alkaline secretion (Hubel, 1972). This is supported by more recent findings of rises in plasma secretin measured by radioimmunoassay after intraduodenal acid in man (Ward and Bloom, 1974, 1975; Bloom and Ward, 1975) and in dogs (Boden et al., 1974). In the dog a secretin infusion of $0.4 \mathrm{CU} / \mathrm{kg} / \mathrm{h}$ produced an pancreatic bicarbonate response equal to that of a natural meal when the $\mathrm{pH}$ was held constant at 5.0 (Grossman and Konturek, 1974). However, the release of secretin from the duodenum is said to require an intraluminal $\mathrm{pH}$ of less than 4.5 and this is achieved in the duodenum for only limited periods after a meal as there is considerable alkaline secretion. Plasma secretin in man has not been shown to increase after a meal (Bloom, 1975) and a rise in plasma secretin has been reported in man only after acidification of the distal duodenum with pure $0 \cdot 1$ molar hydrochloric acid, which is certainly not a physiological stimulus. There has been considerable debate, therefore, concerning the role of secretinfor example, in 'Is secretin secreted?' (Wormsley, 1973). The present study using exogenous infusions

Address for communications: Dr S. R. Bloom, 3rd Floor Cyclotron Building, Royal Postgraduate Medical School, Hammersmith Hospital, Du Cane Road, London W12 0HS.

Accepted for publication 21 January 1977 of pure synthetic secretin was undertaken to assess the plasma level associated with the half maximal pancreatic response to help clarify the physiological role of secretin.

\section{Methods}

Six male subjects (mean age 36.5 years, range $23-42$ years) in good health and free of any evidence of gastrointestinal disease participated as volunteers in this study. Each was studied after overnight fast in the recumbent position. Continuous duodenal drainage was via a modified Lagerlof tube and recovery of duodenal fluid corrected by continuous addition of an inert marker as previously described (Tympner et al., 1974). Secretin was synthesised and purified as earlier described (Wünsch et al., 1972), $1 \mu \mathrm{g}$ synthetic secretin corresponding to 3.9 CU natural secretin (Lehnert et al., 1973).

After a basal period of 30 minutes four consecutive continuous infusions of synthetic secretin were started, each lasting 60 minutes. The dose of secretin was triplicated from one infusion to the next, going from $0 \cdot 1 \mathrm{CU} / \mathrm{kg} / \mathrm{h}$ to $2 \cdot 7 \mathrm{CU} / \mathrm{kg} / \mathrm{h}$. Blood was withdrawn from an antecubital vein into a heparinsed tube with $1000 \mathrm{KIU}$ aprotinin (Trasylol) added per $1 \mathrm{ml}$ blood, then rapidly centrifuged and the plasma frozen at $-20^{\circ} \mathrm{C}$. Samples were taken at 10 minute intervals before and after the infusions of secretin and at five minute intervals during the infusions.

Duodenal bicarbonate concentration was mea- 
sured by titration in an atmosphere of $\mathrm{N}_{2}$ and bicarbonate secretin determined as earlier described (Tympner et al., 1974).

Plasma secretin immunoreactivity was determined by radioimmunoassay. Antisera were raised in rabbits to pure porcine secretin coupled by carbodiimide condensation to bovine serum albumin (molar ratio 2:1). Subcutaneous injections of $25 \mu \mathrm{g}$ secretin per rabbit in complete Freund's adjuvant were given at three monthly intervals and antisera harvested at one year. The antisera (SC10) of highest affinity reacted most avidly with whole secretin but also showed some partial reaction with $\mathrm{C}$ terminal, though not $\mathrm{N}$ terminal, secretin fragments. Chromatography of crude extracts of human jejunum demonstrated only a single peak of secretin immunoreactivity eluting in identical position to pure porcine secretin. No reaction was noted with 10 nmol/1 gastric inhibitory polypeptide, vasoactive intestinal peptide or glucagon, three hormonal peptides with sequence similarities to porcine secretin. Duplicate assay tubes were set up with 160 $\mu \mathrm{l}$ plasma and $640 \mu \mathrm{l} 0.05 \mathrm{M}$ acetate buffer, $\mathrm{pH} 5.0$, containing antiserum (final dilution 1:300 000), radioactive secretin label ( $1 \mathrm{fmol} /$ tube) and $500 \mathrm{KIU}$ aprotinin (Trasylol). After six days incubation at $4^{\circ} \mathrm{C}$ separation of antibody bound from free label was achieved by addition of $16 \mathrm{mg}$ charcoal suspension, in $0.5 \mathrm{ml}$, to each assay tube followed by centrifugation and separation of supernatant. Secretin antibodies, covalently coupled to sepharose beads by the cyanogen bromide technique (Pharmacia Ltd) were used as a specific immunoabsorbent to produce a pooled secretin-free reference plasma. Known amounts of pure secretin were then reintroduced to this plasma to produce the assay standards. The secretin $I^{125}$ label was prepared from pure synthetic secretin by the lactoperoxidase technique (Holohan et al., 1974). Trace iodination of the secretin (about $5 \%$ ) minimised peptide damage and pure monoiodinated secretin was then separated from non-iodinated secretin by high resolution ion exchange chromatography on a $40 \mathrm{ml}$ SP Sephadex T25 column run over 48 hours in $0.25 \mathrm{M}$ pH 5.0 acetate buffer. The secretin $\mathrm{I}^{\mathbf{1 2 5}}$ was very stable and could be used for assay purposes for up to six months. The secretin content of unknown plasma samples was similarly stable (stored below $-20^{\circ} \mathrm{C}$ ) and assayable secretin content was found little changed after two years storage. The assay could detect changes in plasma secretin of $1.5 \mathrm{pmol} / 1$ with $95 \%$ confidence and addition of plasma containing $7.5 \mathrm{pmol} / \mathrm{l}$ secretin caused a drop in the percent label bound from $50 \%$ (zero point) of at least $10 \%$ (Fig. 1). Intra-assay variation was $4.5 \%$ and interassay variation $10 \%$.

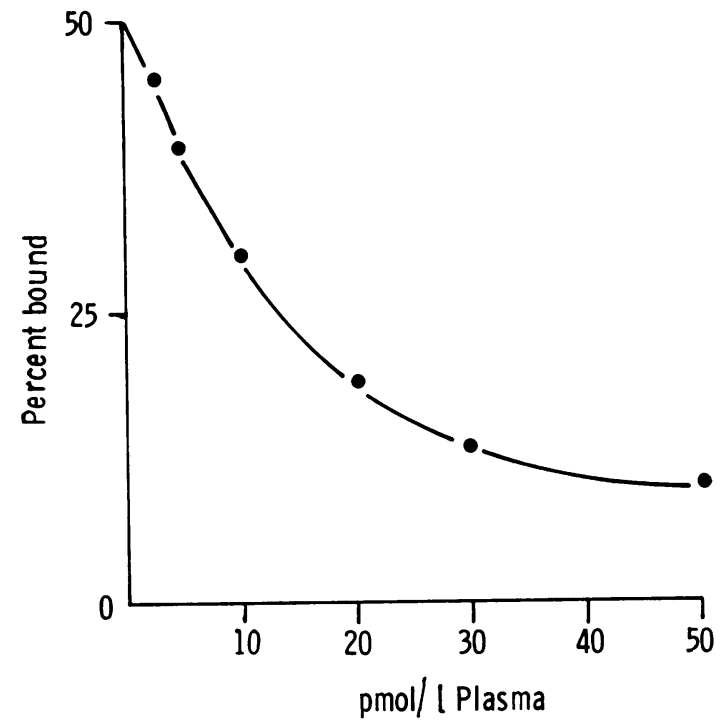

Fig. 1 Radioimmunoassay standard curve. Each point is a mean of two duplicates.

\section{Results}

Figure 2 shows plasma concentrations of secretin immunoreactivity during the study. The ratio of the mean incremental plasma levels at the different infusion rates were 1 to 2.8 to 10.0 to 30.5 reflecting very closely the grading of the infusion secretin content. At the end of the last infusion there was a rapid fall in the plasma secretin to only $8 \%$ of the maximal increment after 10 minutes. Although there is not sufficient data for accurate calculation of the half life of secretin, an approximate value of about 2.8 minutes can be estimated.

Recovery of duodenal bicarbonate increased stepwise during the infusions to a maximum of $33 \pm 4$ $\mathrm{mEq} / \mathrm{h}$ secreted in a volume of $363 \pm 80.8 \mathrm{ml} / \mathrm{h}$ (Table). There was only a small further increment of both bicarbonate output and volume between the 0.9 and $2.7 \mathrm{CU} / \mathrm{kg} / \mathrm{h}$ infusions. The semilogarithmic plot of secretin plasma immunoreactivity and duodenal bicarbonate secretion is shown in Fig. 3. It can be seen that there is a marked increase of bicarbonate output at very low plasma secretin levels. When each bicarbonate output is expressed in percent of the individual maximal response (Fig. 4) half maximal bicarbonate output is observed at a plasma secretin level of $22 \mathrm{pmol} / \mathrm{l}$.

\section{Discussion}

To our knowledge the present study gives for the 


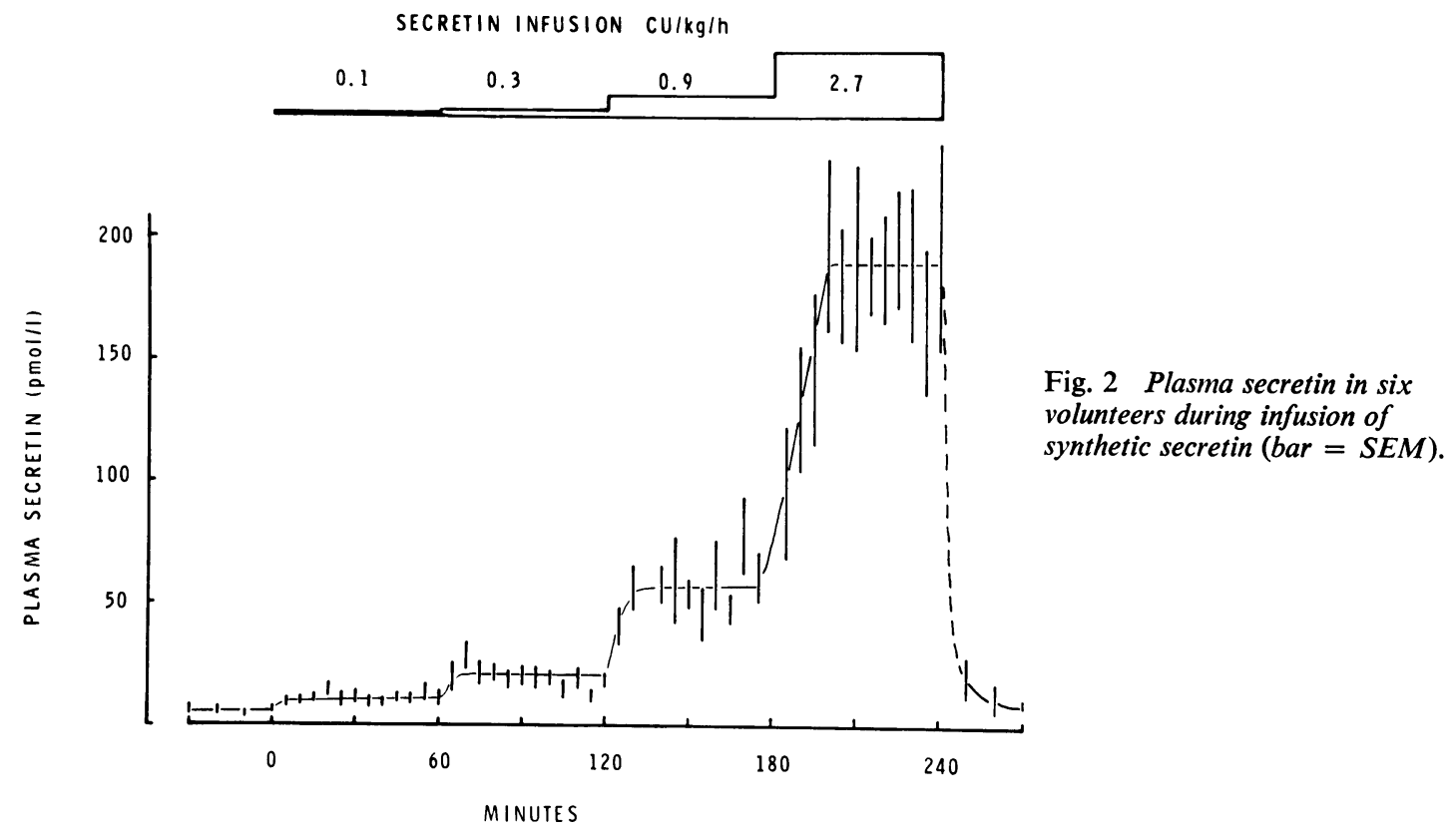

Table Bicarbonate concentrations, bicarbonate output, and volumes of duodenal aspirates during secretin infusions of $0 \cdot 1,0 \cdot 3,0.9$ and $2.7 \mathrm{CU} / \mathrm{kg} / \mathrm{h}$

\begin{tabular}{|c|c|c|c|c|}
\hline \multirow[b]{2}{*}{$n=6$} & \multicolumn{4}{|c|}{ Secretin infusion $(C U / \mathrm{kg} / \mathrm{h})$} \\
\hline & $0 \cdot 1$ & $0 \cdot 3$ & 0.9 & $2 \cdot 7$ \\
\hline $\begin{array}{l}\text { Bicarbonate concentration } \\
(\mathrm{mEq} / \mathrm{l}) \\
\pm \text { SEM } \\
\text { Bicarbonate output }(\mathrm{mEq} / \mathrm{h}) \\
\pm \text { SEM } \\
\text { Volume }(\mathrm{ml} / \mathrm{h}) \\
\pm \text { SEM }\end{array}$ & $\begin{array}{r}56 \cdot 9 \\
11 \cdot 1 \\
6 \cdot 3 \\
1 \cdot 6 \\
106 \\
17 \cdot 4\end{array}$ & $\begin{array}{r}87 \cdot 8 \\
9 \cdot 3 \\
15 \cdot 0 \\
2 \cdot 0 \\
170 \\
16 \cdot 0\end{array}$ & $\begin{array}{r}92 \cdot 8 \\
7 \cdot 6 \\
29 \cdot 8 \\
5 \cdot 2 \\
322 \\
49 \cdot 7\end{array}$ & $\begin{array}{r}76 \cdot 1 \\
4 \cdot 6 \\
33 \cdot 0 \\
4 \cdot 0 \\
363 \\
80 \cdot 8\end{array}$ \\
\hline
\end{tabular}

first time the correlation between exocrine pancreatic function and plasma secretin and also an estimate of the plasma secretin concentration necessary for half maximal stimulation of bicarbonate output. These results indicate that a small increment of plasma secretin is capable on its own of inducing a pancreatic bicarbonate secretion and the rise in concentration required is similar to that produced endogenously in man by acidification of the distal duodenum when measured with an identical assay system (Bloom, 1975).

This type of study has often been suggested but no method previously available was sufficiently sensitive to assay the low levels of secretin present in human plasma. The development of a high specificity radioimmunoassay capable of measuring normal fasting levels of secretin in man has now allowed these experiments to be performed.
The present study was conducted with porcine secretin in man. The amino acid sequence of human secretin is not known and may be different. There is some evidence, however, that little species differences occur. Firstly porcine secretin acts fairly uniformly from species to species always giving rise to a similar



Fig. 3 Dose response curve of duodenal bicarbonate output and plasma secretin immunoreactivity, as Fig. 2. The vertical line through each point indicates the SEM of bicarbonate output and the horizontal line the SEM of plasma secretin. 


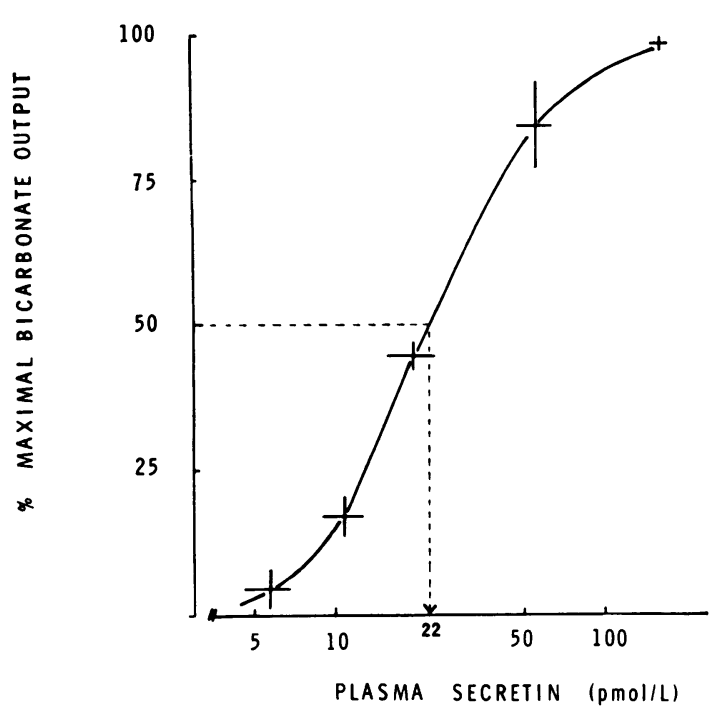

Fig. 4 Dose response curve of duodenal bicarbonate output, expressed as a percent of each subject's maximum, and plasma secretin immunoreactivity (SEM bars as in Fig. 3).

bicarbonate juice production (Hubel, 1972). Secondly, the S-cells of the duodenum and upper jejunum in man can be detected immunocytochemically and thus must contain a substance reacting with an antibody raised against porcine secretin (Polak et al., 1971; Robinson et al., 1975). Thirdly, we have observed that extracts of primate duodenum contain immunoreactive material which chromatographically moves identically to porcine secretin (Bryant and Bloom, 1975). Finally, immunoreactive secretin levels in the pig measured with our assay do not differ greatly from those in man (Bloom et al., unpublished observation).

The maximal bicarbonate secretion observed in this study is of the same order of magnitude as has been reported by others using highly purified natural secretin as well as synthetic secretin (Wormsley, 1968; Petersen, 1970; Konturek, 1970; Berstad et al., 1974; Gutierez and Baron, 1973; Farooq et al., 1974; Vaysse et al., 1974). It can, therefore, be assumed that our higher dose of $2.7 \mathrm{CU} / \mathrm{kg} / \mathrm{h}$ was sufficiently large to give virtually maximal response in the subjects studied. Two of the six had already achieved maximal secretion at the third dose level $(0.9 \mathrm{CU} / \mathrm{kg} /$ h). The use of synthetic secretin assures absence of contamination with other hormones and response may therefore be attributed to the infused secretin. The plasma levels achieved during each infusion rose closely parallel with the infusion rates. This suggests that in man secretin clearance follows first order kinetics within the observed dose range. The roughly estimated half life for secretin of $2 \cdot 8$ minutes may therefore be close to the true value. This is supported by similar data obtained from dogs (Boden $e t$ al., 1974; Lehnert et al., 1974).

The plasma secretin level of $22 \mathrm{pmol} / 1$ for half maximal pancreas stimulation in this study compares closely with previously reported endogenous plasma secretin concentrations during duodenal acidification of $18.5 \mathrm{pmol} / \mathrm{l}$ (Ward and Bloom, 1975) and after an oral ,lemon drink of $16 \cdot 1 \mathrm{pmol} / 1$ (Häcki et al., 1976). This suggests that the rise in endogenous circulating secretin levels may have a significant influence in increasing pancreatic secretion in thesecircumstances. By contrast, after a meal no statistically significant rise in secretin has been reported. This may be because the release of secretin is phasic and, with the short half life, concentrations rapidly return to basal. As the timing of secretion release may vary from individual to individual, a very large number of subjects may be required for statistical significance. Further, the sensitivity of the present secretin assays may still not be adequate to detect small rises. In its natural physiological setting, however, secretin may be far more effective than in the fasting state. It has convincingly been shown that cholecystokinin at least doubles the effectiveness of secretin at lower dose levels (Vaysse et al., 1974) and cholecystokinin is probably significantly raised during duodenal acidification (Konturek et al., 1974). Thus a smaller secretin increment than seen after intraduodenal acid may be an equally effective bicarbonate stimulus in the postprandial state.

We would like to express our thanks to Professor Viktor Mutt for his kind gift of pure natural porcine secretin.

\section{References}

Berstad, A., Roland, M., Petersen, H., and Liavag, I. (1974). The pancreatic exocrine secretion in duodenal ulcer patients before and after selective proximal vagotomy of the stomach. Scandinavian Journal of Gastroenterology, 9, 431436.

Bloom, S. R. (1975). The development of a radioimmunoassay for secretin. In Gastrointestinal Hormones, pp. $257-$ 268. Edited by J. C. Thompson. Texas University Press: Austin.

Bloom, S. R., and Ward, A. S. (1975). Failure of secretin release in patients with duodenal ulcer. British Medical Journal, 1, 126-127.

Boden, G., Essa, N., Owen, O. E., and Reichle, F. A. (1974). Effects of intraduodenal administration of $\mathrm{HCl}$ and glucose on circulating immunoreactive secretin and insulin concentrations. Journal of Clinical Investigation, 53, 11851193.

Bryant, M. G., and Bloom, S. R. (1975). Characterization of the new gastrointestinal hormones. (Abstract). Gut, 16, 840 . 
Farooq, O., Sturdevant, R. A. L., and Isenberg, J. I. (1974). Comparison of synthetic and natural porcine secretins on human pancreatic secretion. Gastroenterology, 66, 204-209.

Gutierrez, L. V., and Baron, J. H. (1973). Maximum bicarbonate response to intravenous infusions of 'GIH' secretin in man. Clinical Science and Molecular Medicine, 45, 859862.

Grossman, M. I., and Konturek, S. J. (1974). Gastric acid does drive pancreatic bicarbonate secretion. Scandinavian Journal of Gastroenterology, 9, 299-302.

Häecki, W. H., Belohlavek, D., Bloom, S. R., Demling, L., Domschke, W., Domschke, S., Galariotis, C., Mallinson, C., Mitznegg, P., and Wuensch, E. (1976). Secretin pharmacokinetics and plasma levels for half maximum bicarbonate response in man. Gut, 17, 393,

Holohan, K. N., Murphy, R. F., Buchanan, K. D., and Elmore, D. T. (1974). Enzymic iodination of polypeptide hormones for radioimmunoassay. Clinica Chimica Acta, 45, 153-155.

Hubel, K. A. (1972). Secretin: a long progress note. Gastroenterology, 62, 318-341.

Jorpes, J. E., and Mutt, V. (1961). On the biological activity and amino acid composition of secretin. Acta Chemica Scandinavica, 15, 1790-1791.

Konturek, S. J. (1970). Pancreatic dose response cures to intravenous secretin in man. Gastroenterology, 58, 828-832.

Konturek, S. J., Radecki, T., and Thor, P. (1974). Comparison of endogenous release of secretin and cholecystokinin in proximal and distal duodenum in the dog. Scandinavian Journal of Gastroenterology, 9, 153-157.

Lehnert, P., Stahlheber, H., Forell, M. M., Fullner, R., Fruehauf, S., Fritz, H., Hutzel, M., and Werle, E. (1974). Studies on the elimination of secretin and cholecystokinin with regard to the kinetics of exocrine pancreatic secretion. Digestion, 11, 51-63.

Lehnert, P., Stahlheber, H., Roder, O., Zoelch, M., Forell, M. M., Wuensch, E., Jaeger, E., and Martens, H. L. (1973). Bestimmung der biologischen Aktivitaet von synthetischem sekretin. Klinische Wochenschriften, 51, 44-46.

Petersen, H. (1970). The effect of pure natural secretin on the bicarbonate secretin into the duodenum in man. Scandinavian Journal of Gastroenterology, 5, 105-111.

Polak, J. M., Coulling, I., Bloom, S. R., and Pearse, A. G. E. (1971). Immunofluorescent localization of secretin and enteroglucagon in human intestinal mucosa. Scandinavian Journal of Gastroenterology, 6, 739-744.

Robinson, G., and Dawson, I. (1975). Immunochemical studies of the endocrine cells of the gastrointestinal tract. II An immunoperoxide technique for the localization of secretin containing cells in human duodenum. Journal of Clinical Pathology, 28, 631.635.

Tympner, F., Domschke, S., Domschke, W., Classen, M., and Demling, L. (1974). Reproducibility of the response to secretin and secretin plus pancreozymin in man. Scandinavian Journal of Gastroenterology, 9, 377-381.

Vaysse, N., Laval, J., Duffaut, M., and Ribet, A. (1974). Effect of secretin and graded doses of CCK-PZ on pancreatic secretion in man. American Journal of Digestive Diseases, 19, 887-894.

Ward, A. S., and Bloom, S. R. (1974). The role of secretin in the inhibition of gastric secretion by intraduodenal acid. Gut, 15, 889-897.

Ward, A. S., and Bloom, S. R. (1975). Effect of vagotomy on secretin release in man. Gut, 16, 951-956.

Wormsley, K. G. (1968). Response to secretin in man. Gastroenterology, 54, 197-209.

Wormsley, K. G. (1969). A comparison of the response to secretin, pancreozymin and a combination of these hormones, in man. Scandinavian Journal of Gastroenterology, 4, 413-417.

Wormsley, K. G. (1973). Progress report. Is secretin secreted? Gut, 14, 743-751.

Wünsch, E., Jaeger, E., Deffner, M., Scharf, A., and Lehnert, P. (1972). Zur synthese des Sekretins, VI Reindarstellung des synthetischen Sekretins. Chemische Berichte, 105, 25152522. 